\title{
L-Theanine Ameliorates D-Galactose-Induced Brain Damage in Rats via Inhibiting AGE Formation and Regulating Sirtuin1 and BDNF Signaling Pathways
}

\author{
Li Zeng $\mathbb{D}^{1,2,3}$ Ling Lin, ${ }^{1,3}$ Ling Chen, ${ }^{1,3}$ Wenjun Xiao $\mathbb{D}^{1,3}$ and Zhihua Gong $\mathbb{D}^{1,3}$ \\ ${ }^{1}$ Key Lab of Tea Science of Ministry of Education, Hunan Agricultural University, Changsha, Hunan 410128, China \\ ${ }^{2}$ School of Pharmacy, Shaoyang University, Shaoyang 422000, China \\ ${ }^{3}$ National Research Center of Engineering and Technology for Utilization of Botanical Functional Ingredients, \\ Hunan Agricultural University, Changsha 410128, China
}

Correspondence should be addressed to Wenjun Xiao; xiaowenjun88@sina.com and Zhihua Gong; gzh041211@163.com

Received 25 September 2020; Revised 2 December 2020; Accepted 6 January 2021; Published 20 July 2021

Academic Editor: Nadja Schroder

Copyright (C) 2021 Li Zeng et al. This is an open access article distributed under the Creative Commons Attribution License, which permits unrestricted use, distribution, and reproduction in any medium, provided the original work is properly cited.

\begin{abstract}
The maintenance of homeostasis is essential for mitigating stress and delaying degenerative diseases such as Alzheimer's disease $(\mathrm{AD}) . \mathrm{AD}$ is generally defined as the abnormal production of $\beta$-amyloid $(\mathrm{A} \beta)$ and advanced glycation end products (AGEs). The effects of $\mathrm{L}$-theanine on $\mathrm{A} \beta$ and AGE generation were investigated in this study. Decreased AGEs and $\mathrm{A} \beta_{1-42}$ levels were reflected by increased acetylcholine (ACh) concentration and acetylcholinesterase (AChE) activity inhibition compared to model rats. L-Theanine also inhibited nuclear factor- $\kappa \mathrm{B}$ (p65) protein expression by activating sirtuin 1 (SIRT1), reducing inflammatory factor expression, and downregulating the mRNA and protein expression of AGE receptors (RAGE). Superoxide dismutase 2 and catalase protein expressions were markedly upregulated by L-theanine, whereas oxidative stress-related injury was alleviated. The expression of peroxisome proliferator-activated receptor- $\gamma$ coactivator $1 \alpha$ (PGC- $1 \alpha$ ) was also found to be increased. H\&E staining showed that the apoptosis of hippocampal neurons was mitigated by decreased Bax and cleaved-caspase- 3 protein expression and the increase of Bcl-2 protein expression. Moreover, L-theanine increased the gene and protein expression of brain-derived neurotrophic factor (BDNF). These findings suggest that the potential preventive effects of L-theanine against AD may be attributed to its regulation of SIRT1 and BDNF proteins and its mitigation of AGEs/RAGE signaling pathways in the brain tissue of $\mathrm{AD}$ model rats.
\end{abstract}

\section{Introduction}

Advanced glycation end products (AGEs) accumulate in human and animal serum or tissues with age $[1,2]$. Clinical studies have found that the amount of AGE-modified $\beta$ amyloid protein $(\mathrm{A} \beta)$ in the cerebrospinal fluid of patients with Alzheimer's disease $(\mathrm{AD})$ is three times higher than that in healthy individuals [3]. AD is a progressive neurodegenerative disease associated with abnormal deposition of $A \beta$ in the brain [4]. Under normal conditions, the production and clearance of $A \beta$ in the body are in dynamic equilibrium. When $\mathrm{A} \beta$ metabolism is dysfunctional, this balance is disrupted, and $\mathrm{A} \beta$ accumulates, resulting in neurotoxicity [5]. Oxidative stress, mitochondrial dysfunction, inflammation, and neuronal cell apoptosis are closely related to $\mathrm{AD}$ pathogenesis [6]. Receptor for AGEs (RAGE), a multiligand membrane receptor primarily expressed in neurons and immune cells [7], binds AGEs and $\mathrm{A} \beta$, thus activating various signaling pathways in brain tissues, resulting in oxidative damage, mitochondrial dysfunction, chronic inflammation, protein degeneration, and apoptosis [7-9]. These mechanisms can disrupt brain cell homeostasis, ultimately leading to a degeneration of the normal brain structure and function $[9,10]$.

Since excess D-galactose exceeds the body glucose metabolism capacity, the Maillard reaction can occur between the aldehyde and protein free amino groups, resulting in the formation of AGEs [11, 12]. In addition, in the presence of oxidative stress, glucose produced by D-galactose metabolism is 
oxidized to produce active carbonyl compounds (such as methylacetaldehyde), which also promote the formation of AGEs [1]. Studies have shown that the brain tissue is unable to metabolize excess D-galactose and that the gradual decrease in brain function induced by D-galactose positively correlates with AGE formation, $\mathrm{A} \beta$ deposition, decrease in acetylcholine (ACh) levels, neuronal apoptosis, and loss of brain-derived neurotrophic factor (BDNF) in brain tissues [13]. Sirtuin1 (SIRT1) is an important functional protein in various mammalian metabolic tissues and can regulate the biological processes involved in neurodegenerative diseases, such as inflammation, oxidative stress, mitochondrial function, cell senescence, and apoptosis [14]. Sirtuin1 elicits its effects by activating downstream transcription factors and has shown the potential to attenuate D-galactoseinduced brain aging in rats $[15,16]$. BDNF is a key factor that promotes neuronal survival and development and improves learning and memory [17, 18]. Additionally, SIRT1 and BDNF may be key factors in AGE production and cognitive impairment in D-galactose-induced glycosylation model rats $[19,20]$.

Food nutrition intervention aimed at inhibiting the production of AGEs, reducing the accumulation of $A \beta$ in brain tissue, downregulating the expression of RAGE protein, and maintaining homeostasis in brain tissue may be an effective approach to treat and prevent $\mathrm{AD}[7,21]$. Epidemiological studies have shown that daily tea drinking can reduce the risk of neurodegenerative diseases, such as cognitive decline and cognitive impairment in the elderly [22, 23]. L-Theanine from tea can increase the amount of glutathione (GSH) and $\mathrm{ACh}$ and the activities of antioxidant enzymes, such as superoxide dismutase (SOD), catalase (CAT), and GSHperoxidase $(\mathrm{Px})$; promote the synthesis and secretion of BDNF; decrease the amount of malondialdehyde (MDA); and maintain a balance expression of inflammatory factors in brain tissue, thereby reducing mitochondrial damage induced by external stress, such as cadmium, $\mathrm{A} \beta_{1-42}$, and polychlorinated biphenyls (e.g., Aroclor1254), and inhibiting apoptosis in brain neuronal cells $[23,24]$. At the same time, in vitro studies have shown that L-theanine reduces AGE formation [25]. We have previously reported that Ltheanine can protect the liver, promote AGE metabolism, and reduce the amount of AGEs in the liver and serum by maintaining the balance between oxidative stress and inflammation in the liver tissues of D-galactose-induced model rats $[26,27]$. However, D-galactose can circulate in the blood, therefore reaching various tissues and organs and form AGEs $[1,8]$. To the best of our knowledge, no reports have described the effects of L-theanine on AGE formation in brain tissues.

Therefore, D-galactose-induced glycosylated model rats were used to explore the mechanisms underlying $\mathrm{L}$-theanine maintenance of homeostasis in brain tissues in this study. We further investigated the role of $\mathrm{L}$-theanine in mitigating the effects of adverse factors, such as brain inflammation, oxidative stress, mitochondrial function, cell senescence, and apoptosis mediated by AGEs/RAGE. Our findings may provide a scientific basis for the development of functional products based on L-theanine to promote healthy aging.

\section{Materials and Methods}

2.1. Materials and Reagents. Healthy male Sprague-Dawley rats (6 weeks old, specific pathogen-free, weighing 180200 g) were obtained from Hunan Slack Jingda Experimental Animal Co., Ltd. (China) (animal quality certificate number: 43004700043916). L-Theanine (cat. no. G5388) and D-galactose (cat. no. SMB00395; purity $\geq 99 \%$ ) were purchased from Sigma (St. Louis, MO, USA). Enzyme-linked immunosorbent assay (ELISA) kits for AGEs (cat. no. CSB-E09413r), A $\beta_{1-42}$ (cat. no. CSB-E10786r), tumor necrosis factor- (TNF-) $\alpha$ (cat. no. CSB-E11987r), interleukin- (IL-) $1 \beta$ (cat. no. CSBE08055r), IL-6 (cat. no. CSB-E04640r), and neuronal nitric oxide synthase (nNOS; cat. no. CSB-E14034r) were purchased from Wuhan Huamei Biological Engineering Co., Ltd. (China). Kits for evaluation of the expression or activity of SOD (cat. no. A001-3), CAT (cat. no. A007-1), GSH-Px (cat. no. A005), NOS (cat. no. A014-2), total antioxidant capacity (T-AOC; cat. no. A015-2), MDA (cat. no. A003-1), ACh (cat. no. A105-1), and acetylcholinesterase (AChE; cat. no. A024-1-1) were purchased from Nanjing Jiancheng Institute of Bioengineering (China). Antibodies targeting $\beta$-actin (cat. no. 60008-1-Ig), RAGE (cat. no. 16346-1-AP), SOD2 (cat. no. 24127-1-AP), CAT (cat. no. 14195-1-AP), SIRT1 (cat. no. 13161-1-AP), peroxisome proliferator-activated receptor- $\gamma$ coactivator- (PGC-) $1 \alpha$ (cat. no. 66369-1-Ig), nuclear factor- (NF-) $\kappa \mathrm{B}$ (p65) (cat. no. 10745-1-AP), Bcl-2 (cat. no. 26593-1-AP), Bax (cat. no. 50599-2-Ig), cleavedcaspase-3 (cat. no. 19677-1-AP), and BDNF (cat. no. 66292-1-Ig), as well as horseradish peroxidase (HRP) goat anti-mouse IgG (cat. no. SA00001-1) and HRP goat antirabbit IgG (cat. no. SA00001-2) were purchased from Proteintech Company (USA). Anti-Ace-NF- $\kappa$ B antibodies (p65; cat. no. ab19870) were purchased from Abcam (Cambridge, UK).

2.2. Experimental Animal Design. Rats were housed in separate cages in a room with a constant temperature $\left(25 \pm 2^{\circ} \mathrm{C}\right)$ and humidity (50-60\%), with a light cycle set to $14 \mathrm{~h}$ of light/10 h of darkness. Before the experiment, all 30 rats were provided with standard rat chow and water ad libitum. After 1 week for acclimation, the rats were divided into five groups ( $n=6$ rats/group) according to different treatment methods, as follows: (1) control group (CON), rats were fed the corresponding dose of normal saline according to their body weight, and the corresponding volume of normal saline was injected into the back of the neck; (2) model group (MOD), rats were fed the corresponding dose of physiological saline according to body weight and were injected with $200 \mathrm{mg} / \mathrm{kg}$ body weight (BW) of D-galactose physiological saline solution subcutaneously into the back of the neck; (3) low-dose L-theanine group (L-LT), rats were fed $100 \mathrm{mg} / \mathrm{kg}$ BW of Ltheanine physiological saline solution and were injected with $200 \mathrm{mg} / \mathrm{kg} \mathrm{BW}$ of D-galactose subcutaneously into the back of the neck; (4) medium-dose L-theanine group (M-LT), rats were fed $200 \mathrm{mg} / \mathrm{kg}$ BW of L-theanine physiological saline solution and simultaneously injected with $200 \mathrm{mg} / \mathrm{kg}$ BW of D-galactose into the back of the neck; and (5) high-dose L-theanine group (H-LT), rats were fed $400 \mathrm{mg} / \mathrm{kg} \mathrm{BW}$ of 
L-theanine physiological saline solution and injected with $200 \mathrm{mg} / \mathrm{kg} \mathrm{BW}$ of D-galactose subcutaneously into the back of the neck.

The rats were treated once a day for 56 days. After 8 weeks, all rats fasted but were allowed free access to water ad libitum. Rats were anesthetized by intraperitoneal injection of $3 \%$ pentobarbital sodium, and rat brain tissues were harvested and stored in a cryogenic refrigerator at $-80^{\circ} \mathrm{C}$ (Thermo Corporation, USA). The experimental animal program was approved by the Animal Experiment Ethics Committee of Hunan Agricultural University (No: 015063506, Changsha, China) and was strictly implemented in accordance with the 8th edition of the US Guidelines for the Care and Use of Laboratory Animals.

\subsection{Sample Analysis}

2.3.1. Histopathological Detection and Analysis of Hippocampal Tissue in Experimental Rats. With reference to the methods reported by Zeng et al. [26], the same part of the hippocampal tissue from three rats in each group was embedded in paraffin and stained with hematoxylineosin (H\&E), and pathological changes in the hippocampal tissue were observed under a 400x light microscope (Leica Microsystems AG, Wetzlar, Germany).

2.3.2. Detection of $A G E s$ and $A \beta_{1-42}$ in the Brain Tissues of Experimental Rats Using ELISA. Approximately $0.02 \mathrm{~g}$ tissue was collected from the same part of the brain in each rat, and the amount of AGEs and $\mathrm{A} \beta_{1-42}$ in the brain tissue was detected according to the manufacturer's instructions.

2.3.3. Biochemical Detection of ACh and AChE in Experimental Rat Brain Tissue. Approximately $0.02 \mathrm{~g}$ tissue was collected from the same part of the brain in each rat, and the contents of ACh and AChE in the brain tissues were detected using an enzyme labeling instrument according to the manufacturer's instructions.

2.3.4. Detection of Oxidative Stress in the Brain Tissues of Experimental Rats. Approximately $0.02 \mathrm{~g}$ tissue was collected from the same part of the brain in each rat. The levels of SOD, CAT, GSH-Px, NOS, T-AOC, and MDA in the brain tissues of each group were detected using an enzyme labeling instrument according to the instructions provided by the kit manufacturer.

2.3.5. Detection of Inflammatory Cytokines in the Brain Tissues of Experimental Rats Using ELISA. Approximately $0.02 \mathrm{~g}$ tissue was collected from the same part of the brain in each rat. According to the manufacturer's instructions, the protein contents of TNF- $\alpha$, IL- $1 \beta$, IL-6, and nNOS were measured using an enzyme labeling instrument.

2.3.6. Real-Time Quantitative Polymerase Chain Reaction (qPCR). The mRNA expression levels of RAGE, SIRT1, $P G C-1 \alpha$, and $B D N F$ in brain tissues were measured using qPCR. Approximately $0.05 \mathrm{~g}$ tissue was collected from the same part of the brain in each rat, and total RNA was extracted using TRIzol reagent (Invitrogen, Carlsbad, CA, USA). The RNA was then reverse transcribed into cDNA, and an ABIQuantStudio3 fluorescence qPCR instrument was used for PCR amplification. The PCR cycle parameters were as follows: predenaturation at $95^{\circ} \mathrm{C}$ for $10 \mathrm{~min}$, followed by 40 cycles of denaturation at $95^{\circ} \mathrm{C}$ for $15 \mathrm{~s}$, and annealing at $60^{\circ} \mathrm{C}$ for $60 \mathrm{~s}$. The $2^{-\triangle \Delta C t}$ method was used to calculate the expression level of each gene in each sample relative to that in the control group. The sequences of the target genes were obtained from NCBI, and primers were designed using PrimerPremier5. All primers were synthesized by Shanghai Shenggong Biological Engineering Co., Ltd. (Table 1).

2.3.7. Western Blotting. With reference to the methods reported by Zeng et al. [26], homogenates from $0.05 \mathrm{~g}$ hippocampal tissue from three rats in each group were randomly selected, and protein was extracted after cleavage. Protein concentrations were then determined. Samples were boiled and denatured, and proteins were separated by electrophoresis and transferred to membranes. Membranes were then incubated with appropriate primary antibodies, washed, and incubated with secondary antibodies. Protein bands were detected using enhanced chemiluminescence. The molecular weight and optical density of target bands for RAGE, SOD2, CAT, SIRT1, PGC- $1 \alpha$, NF- $\kappa$ B (p65), Ace-NF- $\kappa$ B (p65), BDNF, Bcl-2, Bax, and cleaved-caspase- 3 were analyzed using a gel image processing system (Media Cybernetics, Inc., Rockville, MD, USA).

2.4. Statistical Analysis. The data were processed using the GraphPadPrism6 software (GraphPad Software, Inc., USA), and the results are expressed as means \pm standard deviations. Single-factor analysis of variance and least significant difference tests were used to compare the significance of differences between groups. Differences with $P$ values $<0.05$ were considered significant.

\section{Results}

3.1. Pathological Changes in the Hippocampal Tissues of Rats in Each Group. Hippocampal neurons in the MOD group, which were induced by D-galactose, were arranged in a more disordered manner and showed higher shrinkage or apoptosis (black arrow) in comparison with the CON group (Figure 1). With the L-theanine treatment, the damage was substantially reduced, resulting in a neat arrangement of the cells. The effects obtained with the highest concentration of L-theanine were similar to the CON group, which indicate a potential protective effect of $\mathrm{L}$-theanine in the hippocampal tissues.

3.2. Effects of $L$-Theanine on AGEs and $A \beta_{1-42}$ in the Brain Tissues of Experimental Rats. As shown in Figure 2, the concentrations of AGEs and $\mathrm{A} \beta_{1-42}$ in the brain tissues of the MOD group were significantly $(P<0.01)$ higher than those of the CON group. Additionally, following the administration of medium $(200 \mathrm{mg} / \mathrm{kg})$ and high-dose $(400 \mathrm{mg} / \mathrm{kg})$ of L-theanine, the concentration of AGEs and $A \beta_{1-42}$ in the brain tissues significantly decreased in a dose-dependent manner. However, there was no significant decrease in the L-LT group. 
Table 1: Primers used for $\mathrm{qPCR}$.

\begin{tabular}{|c|c|c|}
\hline Gene & Forward and reverse primer $\left(5^{\prime}-3^{\prime}\right)$ & $\begin{array}{l}\text { Product } \\
\text { size }(b p)\end{array}$ \\
\hline$\beta$-Actin & $\begin{array}{c}\text { F: ACATCCGTAAAGACCTCTATGCC } \\
\text { R: TACTCCTGCTTGCTGATCCAC }\end{array}$ & 223 \\
\hline$R A G E$ & $\begin{array}{l}\text { F: CTGCCTCTGAACTCACAGCCAATG } \\
\text { R: GTGCCTCCTGGTCTCCTCCTTC }\end{array}$ & 155 \\
\hline SIRT1 & $\begin{array}{c}\text { F: AAAGGAAATATATCCCGGACA } \\
\text { R: TTTGGATTCCTGCAACCTG }\end{array}$ & 134 \\
\hline$P G C-1 \alpha$ & $\begin{array}{l}\text { F: AATCAAGCCACTACAGACACC } \\
\text { R: TCTCTGCGGTATTCGTCCCTC }\end{array}$ & 148 \\
\hline$B D N F$ & $\begin{array}{l}\text { F: GTCCCGGTATCAAAAGGCCAAC } \\
\text { R: AGTGCCTTTTGTCTATGCCCCT }\end{array}$ & 103 \\
\hline
\end{tabular}

3.3. Effects of L-Theanine on ACh and AChE in the Brain Tissues of Experimental Rats. The amounts of ACh and AChE in the brain tissues are shown in Figure 3. Compared with the CON group, the amounts of $\mathrm{ACh}$ and AChE were significantly decreased and increased, respectively, in the brain tissues of the MOD group $(P<0.01)$. Following L-theanine treatment, the level of $\mathrm{ACh}$ and AChE in brain tissues significantly improved and decreased, respectively, in a dose-dependent manner $(P<0.05$ and $P<0.01$, respectively).

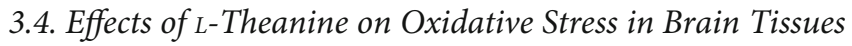
of Experimental Rats. Evaluation of oxidative stress response to L-theanine is shown in Figure 4. SOD, CAT, GSH-Px, and T-AOC activities were significantly decreased, whereas NOS activity and MDA concentration were significantly increased in brain tissues after D-galactose exposure $(P<0.01)$. After administration of medium and high-dose of L-theanine, SOD, CAT, and T-AOC activities were significantly increased, whereas NOS activity and MDA concentration significantly decreased $(P<0.05$ and $P<0.01)$. Similarly, there were no significant changes in oxidative stress levels in brain tissues treated with a low concentration of L-theanine $(P>0.05)$.

3.5. Effects of L-Theanine on Inflammatory Cytokines in Brain Tissues from Experimental Rats. Inflammatory cytokines play important roles in age-related degenerative diseases [28]. As shown in Figure 5, inflammatory factors, including IL- $1 \beta$, IL-6, TNF- $\alpha$, and nNOS, in the brain tissues of the MOD group were significantly higher than those of the CON group $(P<0.01)$. Compared with the MOD group, the levels of IL$1 \beta$, IL- 6 , TNF- $\alpha$, and nNOS in the brain tissues of the $\mathrm{L}$-theanine-treated groups were significantly decreased $(P<0.01)$.

3.6. Effects of L-Theanine on RAGE, SIRT1, PGC-1 $\alpha$, and BDNF mRNA Levels in the Brains of Experimental Rats. As shown in Figure 6, compared with the CON group, RAGE mRNA levels in the brain tissues of the MOD group were significantly increased, whereas those of $P G C-1 \alpha$ and $B D N F$ mRNA significantly decreased $(P<0.01)$. Compared with the MOD group, RAGE mRNA levels in the brain tissues of the L-theanine-treated groups significantly decreased
$(P<0.01)$. In contrast, the levels of SIRT1, PGC-1 $\alpha$, and $B D N F$ mRNAs were significantly increased in the M-LT and H-LT groups $(P<0.01)$.

3.7. Effects of $L$-Theanine on the Expression of Key Proteins in the Brain Tissues of Experimental Rats. As shown in Figure 7, the protein expression levels of RAGE, SIRT1, Ace-NF- $\kappa$ B (p65), and BDNF in the brain tissues of the MOD group were significantly altered in comparison with the CON group $(P<0.01)$. Significant changes in those protein expression levels were observed in the M-LT and H-LT groups $(P<0.05$ or $P<0.01)$, whereas no significant change was observed in brain tissues $(P>0.05)$.

As shown in Figure 8, the expression levels of PGC- $1 \alpha$, SOD2, and CAT proteins in the brain tissues of rats in the MOD group were significantly lower than those of the CON group $(P<0.01)$. Compared with the MOD group, the protein expression levels of SOD2 in the brain tissues of rats in the L-LT group did not significantly change $(P>0.05)$, whereas those of PGC- $1 \alpha$ and CAT significantly increased $(P<0.05)$. The expression levels of PGC- $1 \alpha$, SOD2, and CAT proteins in the brain tissues of rats in the M-LT and H-LT groups were significantly increased $(P<0.01)$.

As shown in Figure 9, compared with the CON group, the significant changes in protein expression levels of Bcl-2, Bax, and cleaved-caspase- 3 were observed in the brain tissues of rats in the MOD group $(P<0.01)$. Compared with the MOD group, the protein expression levels of cleavedcaspase- 3 in the brain tissues of rats in the L-LT group did not significantly change $(P>0.05)$, whereas the protein expression levels of Bcl-2 and Bax were significantly changed $(P<0.01)$. Additionally, significant changes in the protein expression levels of Bcl-2, Bax, and cleaved-caspase- 3 were observed in the brain tissues of rats in the M-LT and H-LT groups $(P<0.01)$.

\section{Discussion}

$\mathrm{A} \beta$ is a transmembrane protein that abnormally accumulates in the brains of patients with $\mathrm{AD}$ and can penetrate the cell membrane of neurons, alter the cell osmotic balance, induce neurotoxicity, and lead to memory impairment and neuronic loss [29]. Notably, AGE concentration positively correlates with the degree of pathological changes in patients with cognitive impairment $[3,30]$. Long-term exposure to a high concentration of D-galactose significantly increases AGEs and $\mathrm{A} \beta_{1-42}$ levels in the brain of mice and results in cognitive impairment $[31,32]$. Reducing $\mathrm{AGEs}$ and $\mathrm{A} \beta_{1-42}$ levels in the brain is essential for the prevention of cognitive impairment. $\mathrm{A} \beta_{1-42}$ concentration in the cerebral cortex and hippocampus was reportedly significantly decreased in mice fed Ltheanine for 5 weeks [33]. We found that the concentrations of AGEs and $\mathrm{A} \beta_{1-42}$ were significantly increased when induced with $\mathrm{D}$-galactose and then decreased after L-theanine treatment, which is consistent with the fact that nutritional intervention with $\mathrm{L}$-theanine effectively reduced the amount of AGEs and $\mathrm{A} \beta_{1-42}$ in brain tissues $[33,34]$. 

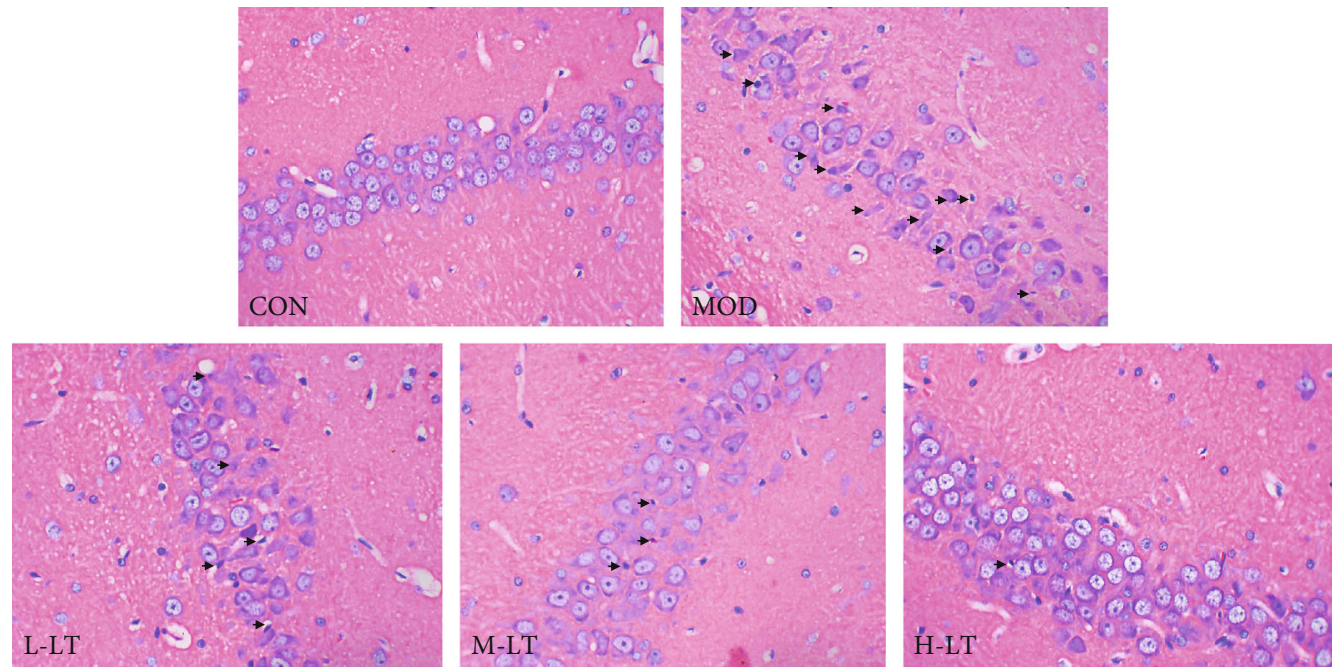

Figure 1: Pathological changes in rats' hippocampal tissues of each group (400x; $n=3)$. The black arrows indicate shrinkage or apoptosis of nerve cells. L-LT: low-dose (100 mg/kg) L-theanine group; M-LT: medium-dose (200 mg/kg) L-theanine group; H-LT: high-dose (400 mg/kg) L-theanine group.
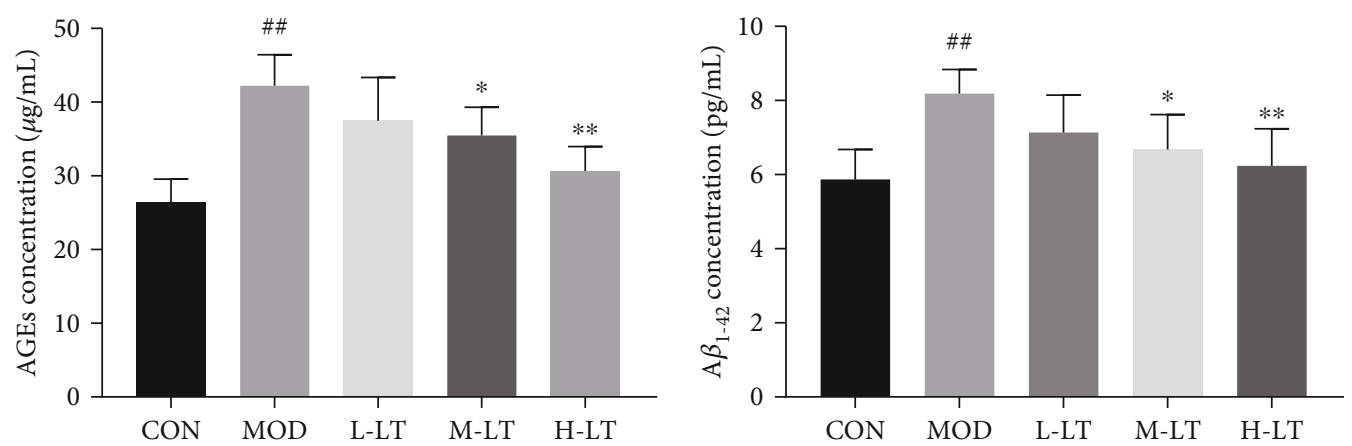

FIGURE 2: AGEs and $\mathrm{A} \beta_{1-42}$ concentrations in rats' brain tissues of each group $(n=6)$. Compared with the CON group: ${ }^{\#} P<0.05$, ${ }^{\# \#} P<0.01$; compared with the MOD group: ${ }^{*} P<0.05,{ }^{* *} P<0.01$. L-LT: low-dose $(100 \mathrm{mg} / \mathrm{kg})$ L-theanine group; M-LT: medium-dose $(200 \mathrm{mg} / \mathrm{kg})$ L-theanine group; H-LT: high-dose $(400 \mathrm{mg} / \mathrm{kg})$ L-theanine group.
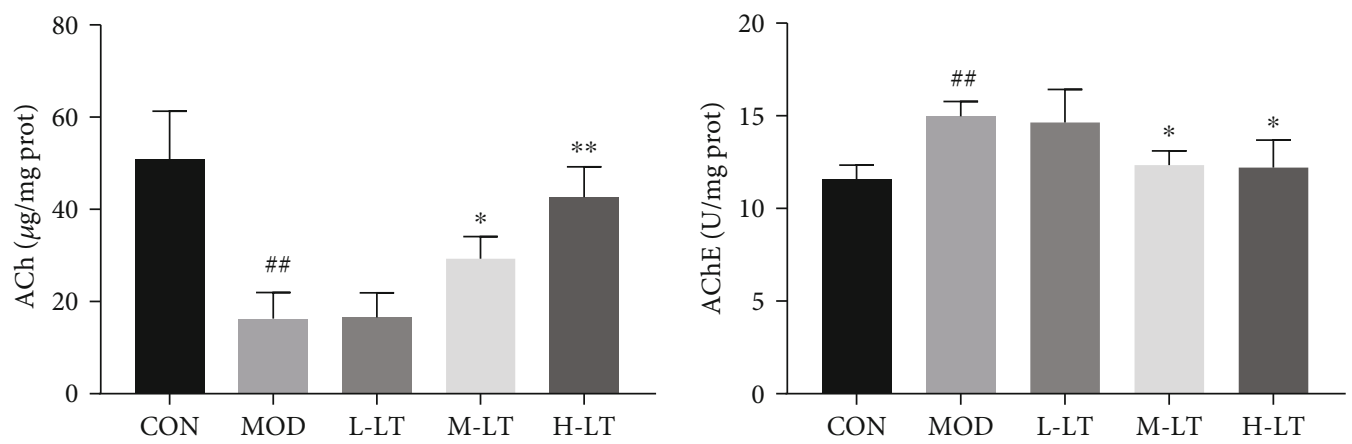

FIgure 3: The concentration of ACh and AChE in rats' brain tissues of each group $(n=6)$. Compared with the CON group: ${ }^{\#} P<0.05$, ${ }^{\#} P<0.01$; compared with the MOD group: ${ }^{*} P<0.05,{ }^{* *} P<0.01$. L-LT: low-dose $(100 \mathrm{mg} / \mathrm{kg})$ L-theanine group; M-LT: medium-dose $(200 \mathrm{mg} / \mathrm{kg})$ L-theanine group; H-LT: high-dose $(400 \mathrm{mg} / \mathrm{kg})$ L-theanine group.

Progressive cognitive impairment is also related to dynamic changes in ACh and AChE activity [35]. In this study, when induced by D-galactose, the activity of $\mathrm{AChE}$ was significantly increased in rat brains. L-Theanine can inhibit ACh degradation by decreasing the activity of AChE in brain damage induced by scopolamine $(1 \mathrm{mg} / \mathrm{kg}$, i.p.) [36]. Similarly, our results showed that L-theanine inhibited the AChE activity and restored normal levels of ACh in brain tissues, thereby repressing the damage caused by AGEs and $\mathrm{A} \beta_{1-42}$. These findings were consistent with the fact that 

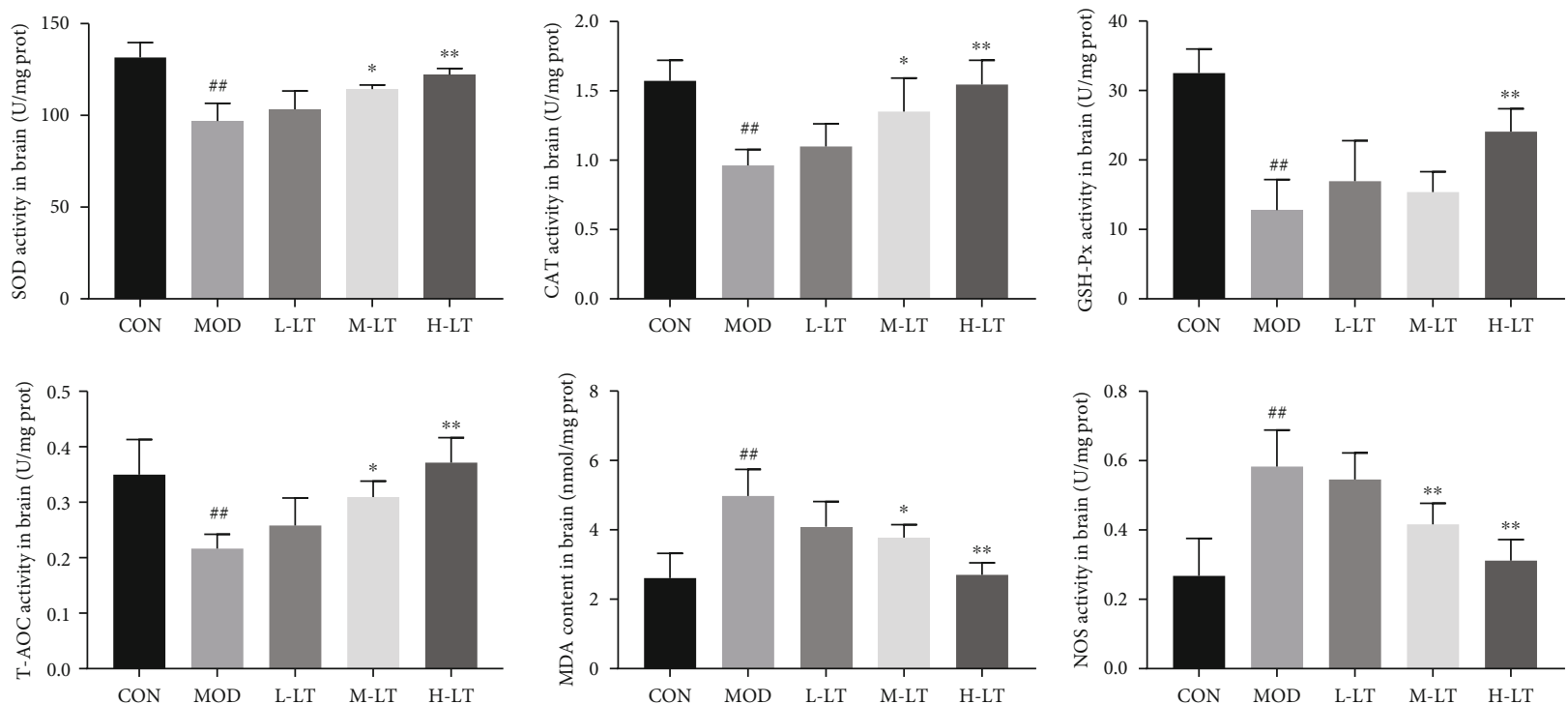

FIGURE 4: Activities and concentrations of oxidative stress-associated markers in rats' brain tissues of each group $(n=6)$. Compared with the CON group: ${ }^{\#} P<0.05,{ }^{\# \#} P<0.01$; compared with the MOD group: ${ }^{*} P<0.05,{ }^{* *} P<0.01$. L-LT: low-dose $(100 \mathrm{mg} / \mathrm{kg}) \mathrm{L}$-theanine group; M-LT: medium-dose $(200 \mathrm{mg} / \mathrm{kg})$ L-theanine group; H-LT: high-dose $(400 \mathrm{mg} / \mathrm{kg})$ L-theanine group.
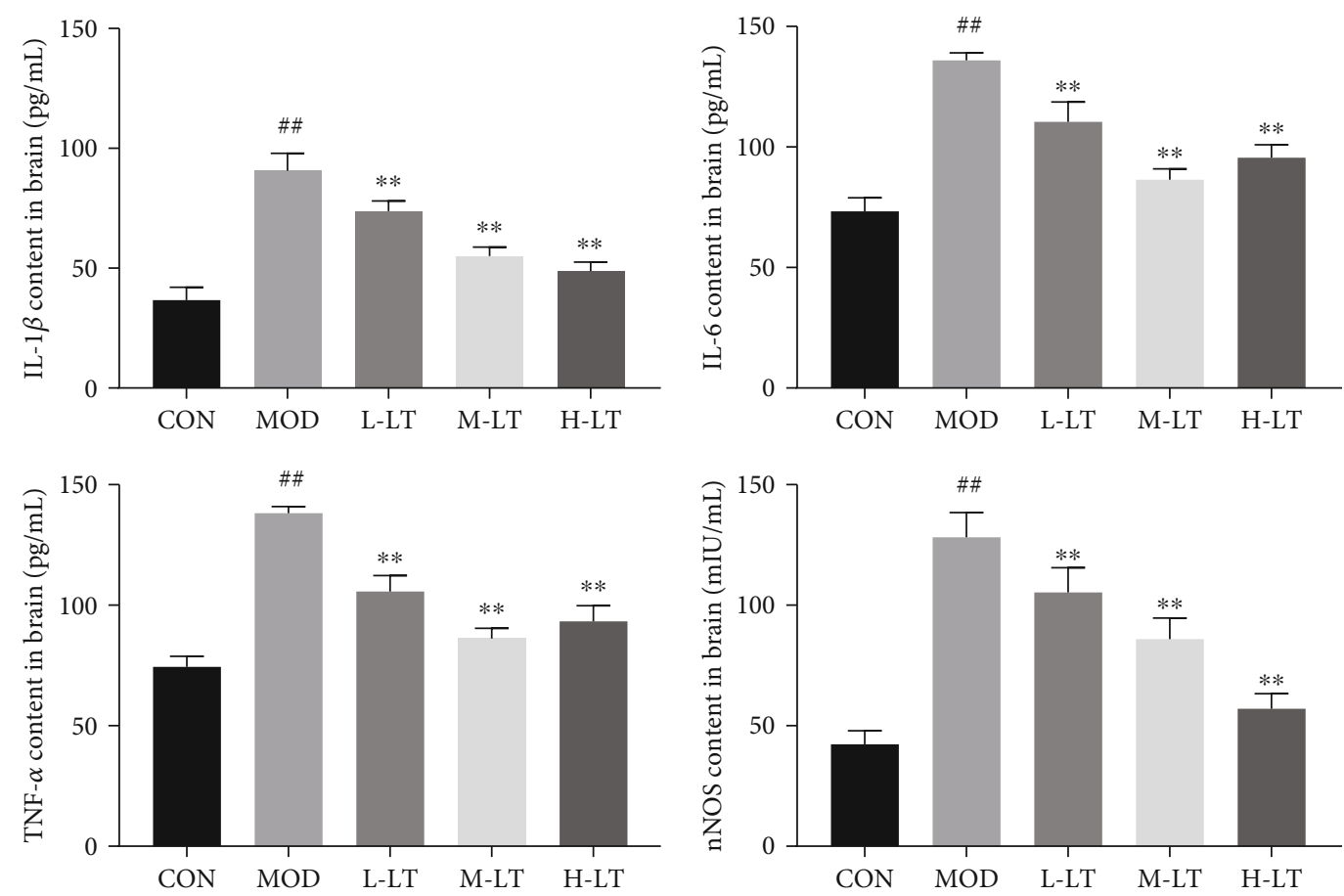

FIGURE 5: Concentrations of IL- $1 \beta$, IL-6, TNF- $\alpha$, and nNOS in rats' brain tissues of each group $(n=6)$. Compared with the CON group: ${ }^{\#} P<0.05$, ${ }^{\# \#} P<0.01$; compared with the MOD group: ${ }^{*} P<0.05,{ }^{* *} P<0.01$. L-LT: low-dose $(100 \mathrm{mg} / \mathrm{kg})$ L-theanine group; M-LT: medium-dose $(200 \mathrm{mg} / \mathrm{kg})$ L-theanine group; H-LT: high-dose $(400 \mathrm{mg} / \mathrm{kg})$ L-theanine group.

L-theanine blocked the increase in $\mathrm{A} \beta_{1-42}$ content and AChE activity induced by external stress and prevented $\mathrm{AD}[33,34,36]$.

AGEs and $\mathrm{A} \beta_{1-42}$ can bind to RAGE and promote intracellular oxidative stress production, with the activation of the RAGE signal pathway $[8,37]$. The brain is the most vulnerable organ to oxidative stress due to its high metabolic activity, high lipid content, and limited antioxidant defense capacity [13]. According to the theory of free radical aging, maintaining the balance of oxidative stress contributes to preventing or delaying age-related diseases [38]. Previous studies have shown that $\mathrm{D}$-galactose induces oxidative stress damage and mitochondrial dysfunction and promotes the production of AGEs $[13,39]$. In this study, we found that the gene and 

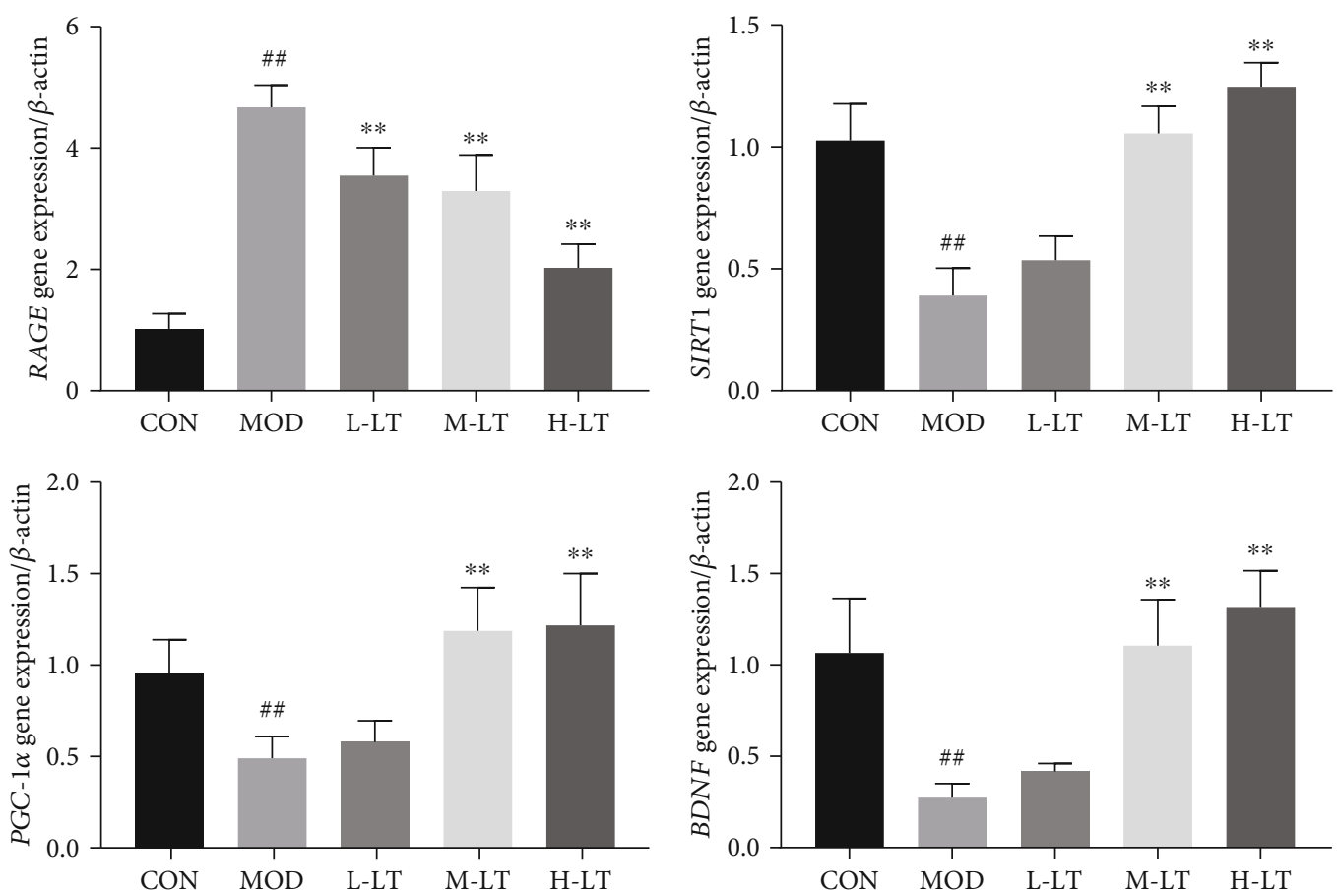

Figure 6: Expression levels of RAGE, SIRT1, $P G C-1 \alpha$, and BDNF mRNAs in rats' brain tissues of each group $(n=6)$. Compared with the CON group: ${ }^{\#} P<0.05,{ }^{\# \#} P<0.01$; compared with the MOD group: ${ }^{*} P<0.05,{ }^{* *} P<0.01$. L-LT: low-dose $(100 \mathrm{mg} / \mathrm{kg})$ L-theanine group; M-LT: medium-dose $(200 \mathrm{mg} / \mathrm{kg})$ L-theanine group; H-LT: high-dose $(400 \mathrm{mg} / \mathrm{kg})$ L-theanine group.

protein expression levels of RAGE were increased in the brains of D-galactose-induced glycosylated model rats, and significant changes were observed in various oxidative stress indexes. Mitochondria are the primary energy production site for normal cell physiological activities and enhance brain cognitive ability [40]. However, excessive production of active oxidative stress products leads to mitochondrial damage and dysfunction, a key factor in the occurrence of neurodegenerative diseases, such as AD [41]. Studies have shown that PGC- $1 \alpha$ is a key regulator of mitochondrial biosynthesis and function $[40,42]$, whereas antioxidant enzymes such as SOD2 and CAT protect the mitochondria from oxidative stress, exerting neuroprotective effects [43]. L-Theanine increased SOD2 and CAT protein levels in the brains of rats exposed to D-galactose, thereby alleviating the imbalances in oxidative stress components, inhibiting the production of AGEs, and preventing AGE-induced neurotoxicity in brain tissues. L-Theanine also upregulated PGC- $1 \alpha$ mRNA and protein in the brains of D-galactose-treated rats, contributing to normal biosynthesis of mitochondria in rat brain tissues and positively regulating oxidative metabolism. In addition, L-theanine recalibrated the redox balance in the mitochondria to resist the occurrence and development of neurodegenerative diseases [44]. This may be attributed to the antioxidant activity of L-theanine, as reported by Ben and Jo; indeed, L-theanine maintains the normal biological function of mitochondria, thereby reducing neurotoxicity to protect nerve cells $[45,46]$.

Chronic inflammation, which also high related with $\mathrm{AD}$, is a pathological condition characterized by a continuous active inflammatory response and tissue destruction [47].
Persistent oxidative stress injury is also a signal of chronic inflammation and is closely associated with the pathological and physiological changes of many age-related degenerative diseases [48]. Inflammation can mitigate abnormalities and promote tissue healing in acute cases at low levels. However, a long-term high level of inflammation could seriously damage host tissues [49]. The transcription factor NF- $\kappa \mathrm{B}$ is a key factor regulating inflammation. Of note, NF- $\kappa \mathrm{B}$ acetylation activates its regulatory ability. Continuous increases in AceNF- $\kappa \mathrm{B}$ (p65) protein levels promote the secretion of downstream proinflammatory factors, such as IL- $1 \beta$, IL- 6 , and TNF- $\alpha$, and induce systemic inflammation [50]. In addition, activated NF- $\kappa \mathrm{B}$ (p65) positively correlates with high expression of RAGE [51]. Activated NF- $\kappa$ B, RAGE, and proinflammatory factors form a vicious circle, causing a state of persistent pathological inflammation in the brain. As an effective immunomodulator [24, 52, 53], L-theanine was found to inhibit the activation of NF- $\kappa \mathrm{B}$ (p65) and the expression of proinflammatory factors, such as TNF- $\alpha$, IL$1 \beta$, and IL- 6 in the rat brain, thereby promoting resistance to nerve cell damage. Accordingly, L-theanine inhibited Ace-NF- $\kappa$ B protein expression in rat brains exposed to Dgalactose and downregulated RAGE mRNA and protein expression, thus preventing an increase in proinflammatory markers, such as IL- $1 \beta$, nNOS, TNF- $\alpha$, and IL- 6 . These findings suggest that L-theanine could be used to regulate the persistent pathological inflammatory state in the brain tissues of D-galactose-treated model rats and restore inflammatory balance in brain tissues.

Apoptosis is an active form of programmed cell death, which is closely related to $\mathrm{AD}$ lesions and is regulated by 

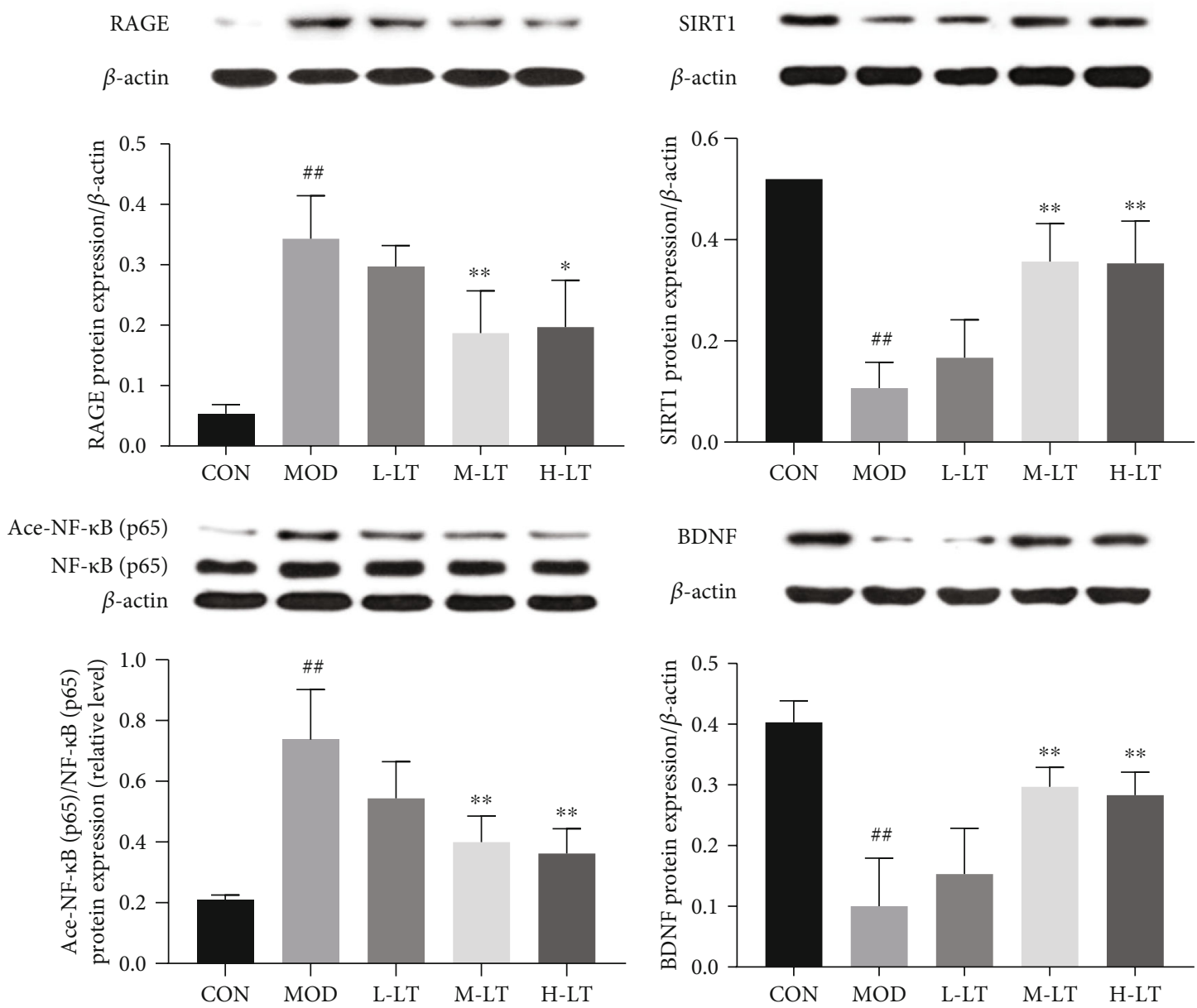

Figure 7: Protein expression of RAGE, SIRT1, Ace-NF- $\kappa$ B (p65), and BDNF in rats' brain tissues of each group ( $n=3$ ). Compared with the CON group: ${ }^{\#} P<0.05$, ${ }^{\# \#} P<0.01$; compared with the MOD group: ${ }^{*} P<0.05,{ }^{* *} P<0.01$. L-LT: low-dose $(100 \mathrm{mg} / \mathrm{kg}) \mathrm{L}-\mathrm{theanine}$ group; M-LT: medium-dose $(200 \mathrm{mg} / \mathrm{kg})$ L-theanine group; H-LT: high-dose $(400 \mathrm{mg} / \mathrm{kg})$ L-theanine group.

specific proteins, including $\mathrm{Bcl}$ proteins and caspases [54]. Cho and Di reported that L-theanine has antineuronal apoptosis effects, suggesting applications in the prevention and treatment of neurodegenerative diseases $[34,55]$. L-Theanine inhibited the expression of the apoptotic proteins, including Bax and cleaved-caspase-3. Furthermore, L-theanine promoted the expression of the antiapoptotic protein $\mathrm{Bcl}-2$, which controls the level of neuronic apoptosis in brain tissues and maintains brain environment stability. Additionally, $H \& E$ staining of hippocampal rat tissues confirmed that L-theanine blocked D-galactose-induced neuronal apoptosis.

Impairment of neuronal plasticity due to normal aging is paralleled by neuronal damage, apoptosis, and reduced cognitive ability [17]. Neurotrophins and their receptors, particularly BDNF, are expressed in highly malleable brain regions (e.g., the hippocampus and cerebral cortex), which are considered molecular mediators of functional and morphological synaptic plasticity. These molecules are also essential for neuronal proliferation, excitability, synaptic transmission, and plasticity $[56,57]$. In addition, BDNF plays a vital role in supporting the survival and growth of sensory and motor neurons, all of which are vital factors for learning and memory [58]. Moreover, some exogenous substances enhance
BDNF expression, thereby inhibiting neuronal apoptosis and reducing neurodegenerative changes $[59,60]$. We found that D-galactose inhibited the expression of BDNF, whereas L-theanine enhanced the expression of BDNF mRNA and protein in the brains of $\mathrm{D}$-galactose-treated rats, thereby preventing D-galactose-induced hippocampal neuron dysfunction. These findings are consistent with a report that L-theanine increases BDNF content in the serum or hippocampal tissue and inhibits the effects of neurotoxicity caused by exogenous stress on neurodegenerative diseases [55]. Furthermore, it has been reported that PGC- $1 \alpha$ overexpression can reverse the inhibition of BDNF mRNA expression in neurons of APP/PS1 transgenic mice [61]. More importantly, the increased expression of upstream PGC- $1 \alpha$ can upregulate the BDNF expression and counteract the effect of $\mathrm{A} \beta_{1-42}$ on neuronal apoptosis $[61,62]$. Collectively, these findings indicate that PGC- $1 \alpha$ plays a pivotal role in BDNF upregulation. Our results suggest that L-theanine may also upregulate the level of PGC- $1 \alpha$ protein in rat hippocampus exposed to D-galactose, recover the level of BDNF, and improve the $\mathrm{D}$-galactose-induced brain damage.

Homeostasis of the internal environment is essential for promoting healthy aging of the body [28]. SIRT1 is a highly 


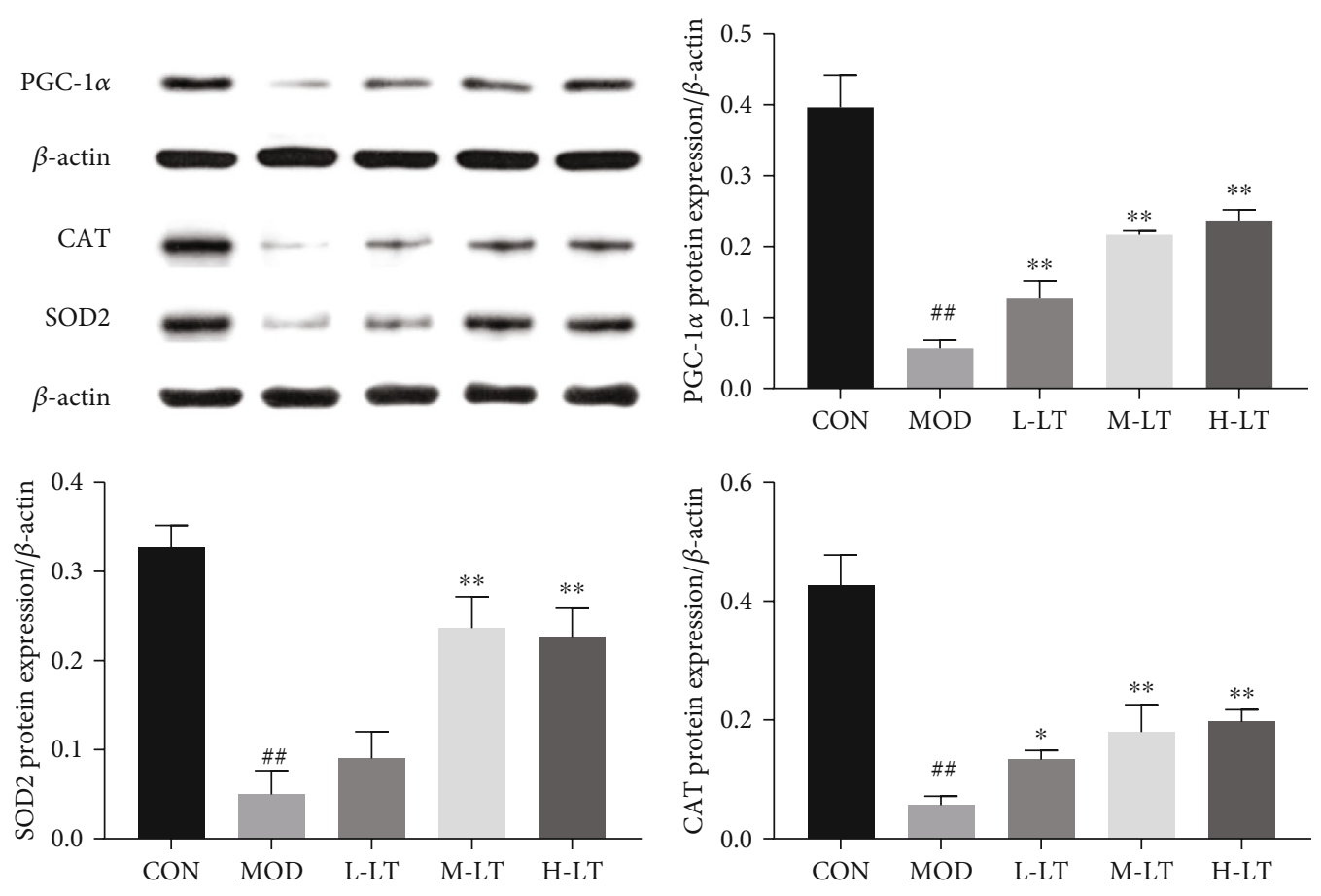

Figure 8: Protein expression of PGC- $1 \alpha$, SOD2, and CAT in rats' brain tissues of each group $(n=3)$. Compared with the CON group: ${ }^{\#} P<0.05,{ }^{\# \#} P<0.01$; compared with the MOD group: ${ }^{*} P<0.05,{ }^{* *} P<0.01$. L-LT: low-dose $(100 \mathrm{mg} / \mathrm{kg})$ L-theanine group; M-LT: medium-dose $(200 \mathrm{mg} / \mathrm{kg})$ L-theanine group; H-LT: high-dose $(400 \mathrm{mg} / \mathrm{kg})$ L-theanine group.
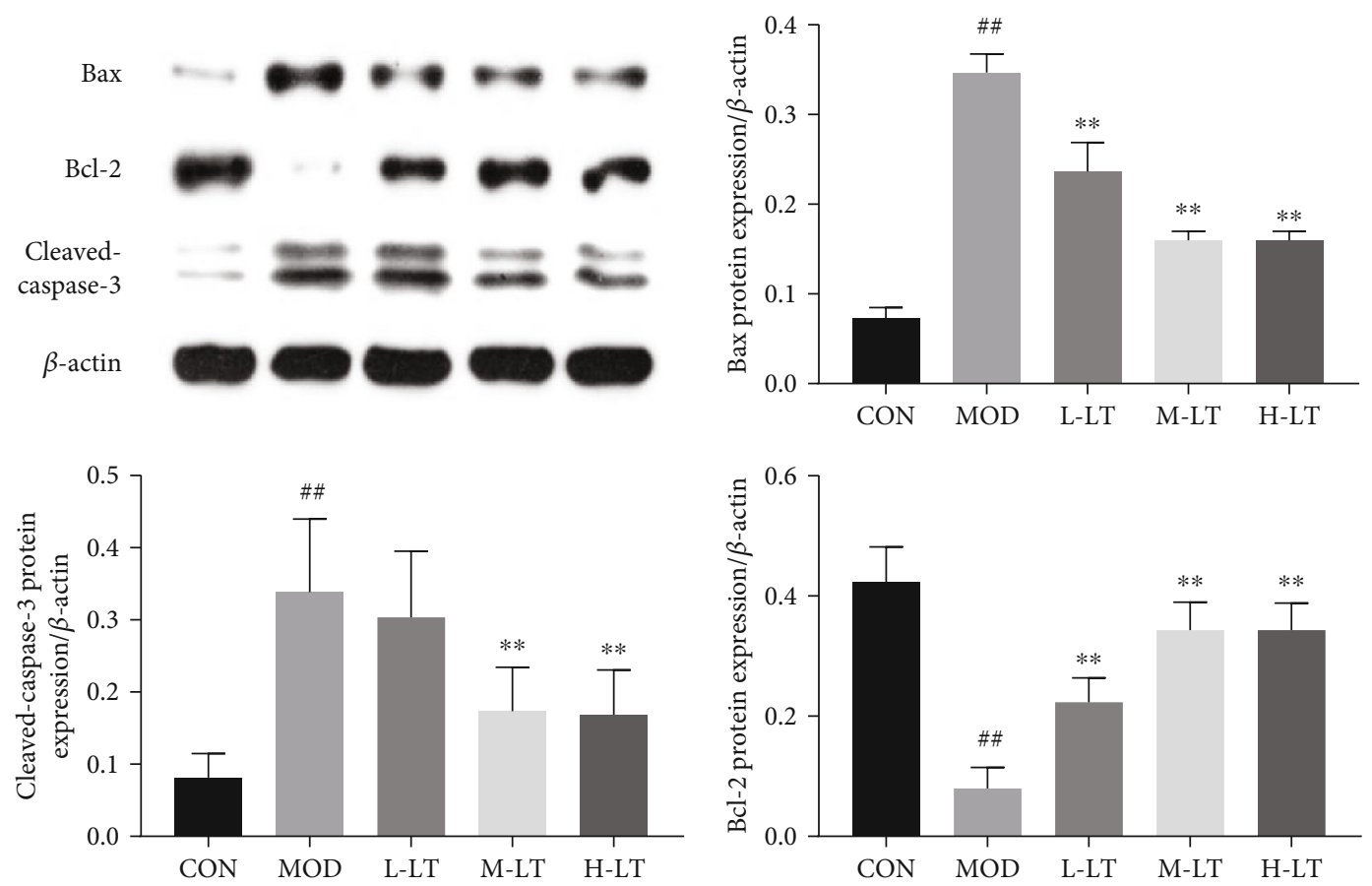

Figure 9: Protein expression of Bcl-2, Bax, and cleaved-caspase- 3 in rats' brain tissues of each group ( $n=3)$. Compared with the CON group: ${ }^{\#} P<0.05$, ${ }^{\#} P<0.01$; compared with the MOD group: ${ }^{*} P<0.05,{ }^{* *} P<0.01$. L-LT: low-dose (100 mg/kg) L-theanine group; M-LT: mediumdose $(200 \mathrm{mg} / \mathrm{kg})$ L-theanine group; H-LT: high-dose $(400 \mathrm{mg} / \mathrm{kg})$ L-theanine group.

conserved protein that functions in deacetylation and maintenance of the homeostasis of the internal environment $[28,63]$. SIRT1 is involved in several biological pro- cesses, such as oxidative stress, inflammatory reactions, apoptosis and senescence, mitochondrial biosynthesis, glucose and lipid metabolism, and oxidative metabolism 


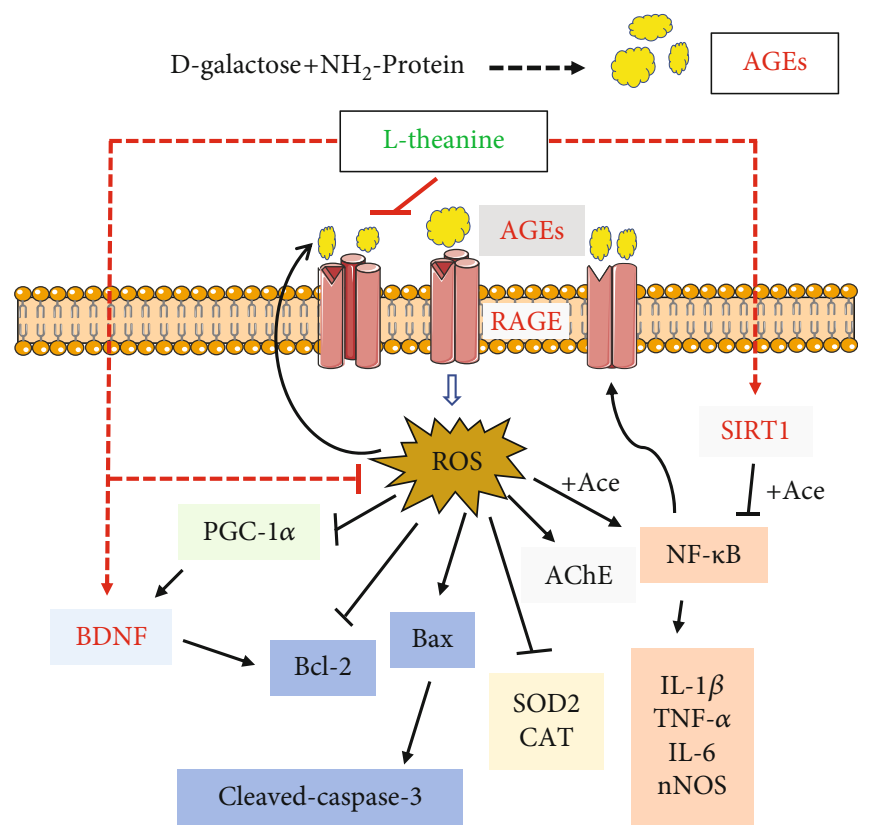

FIGURE 10: Potential alleviation mechanisms of L-theanine on brain injury in D-galactose-induced glycosylation model rats.

mediated by downstream RAGE factors, such as SOD2, CAT, NF- $\kappa$ B, Bax, and PGC- $1 \alpha[63,64]$. Moreover, SIRT1 plays important roles in inhibiting the occurrence and development of neurodegenerative diseases, protecting nerve cells, and maintaining normal nerve function [14]. Abnormal increases in AGEs and $\mathrm{A} \beta_{1-42}$ induced by $\mathrm{D}$-galactose can mediate inflammation, oxidative stress injury, mitochondrial dysfunction, and apoptosis and decrease BDNF and ACh levels, resulting in induction of the pathological processes of neurodegenerative diseases $[13,65,66]$. Therefore, reducing the concentrations of AGEs and $\mathrm{A} \beta_{1-42}$ and the RAGE expression in brain tissue is critical for preventing and treating neurodegenerative diseases. In our study, we showed that L-theanine inhibited the accumulation of AGEs and $A \beta_{1-42}$ in the brains of model rats exposed to D-galactose and facilitate the maintenance of normal BDNF and ACh levels. Additionally, L-theanine blocked NF- $\kappa \mathrm{B}$ acetylation and downregulated RAGE mRNA and protein levels by activating SIRT1 [67]. Furthermore, L-theanine maintained the balance of inflammatory responses, modulated redox balance and mitochondrial biosynthesis, and reduced neuronal apoptosis in the hippocampus, thereby facilitating homeostasis of brain tissue and alleviating brain injury induced by D-galactose.

Prevention and treatment of D-galactose-induced brain injury by L-theanine could apply to other tissues besides the brain. For example, previous studies have shown that agerelated degenerative diseases can be controlled or attenuated by activating the energy metabolite adenylate-activated protein kinase (AMPK) [68]. The longevity protein SIRT1 is required for AMPK activity [69]. We have previously shown that $\mathrm{L}$-theanine has protective effects in the livers of $\mathrm{D}$-galactose-treated rats and promotes glucose metabolism through the AMPK signaling pathway, resulting in reduced sugar concentrations in the body $[26,27]$. Therefore, we speculate that $\mathrm{L}$-theanine can inhibit the positive reaction of Schiff base

formation between D-galactose and free amino groups, along with its reduction of $\mathrm{AGEs}$ and $\mathrm{A} \beta_{1-42}$ concentrations, thereby alleviating $\mathrm{D}$-galactose-induced damage in rats' brain tissues.

Thus, the potential alleviation mechanism of L-theanine on brain injury induced by $\mathrm{D}$-galactose is presented in Figure 10. Treatment with L-theanine decreased $\mathrm{A} \beta_{1-42}$ and mitigated AGEs/RAGE-induced brain damage by upregulating SIRT1 and BDNF proteins.

\section{Conclusion}

L-Theanine was found to mitigate brain damage via inhibiting AGEs/RAGE signaling pathways and upregulating SIRT1 and BDNF, which indicate that L-theanine may be a potential functional food to prevent $\mathrm{AD}$ and promote healthy aging. For future work, studies of further mechanisms of L-theanine on different tissues of rats will be required. It would also be desirable to examine the metabolism of $\mathrm{L}$-theanine in a rat model of D-galactose-induced brain damage.

\section{Abbreviations}

$\mathrm{A} \beta$ :

ACh:

AChE:

AD:

AGEs:

AMPK:

BDNF:

CAT:

$\mathrm{CON}$ :

GSH:

H-LT:

IL:
$\beta$-Amyloid

Acetylcholine

Acetylcholinesterase

Alzheimer's disease

Advanced glycation end products

AMP-activated protein kinase

Brain-derived neurotrophic factor

Catalase

Control group

Glutathione peroxidase

High-dose L-theanine group

Interleukin 


$\begin{array}{ll}\text { L-LT: } & \text { Low-dose L-theanine group } \\ \text { MDA: } & \text { Malondialdehyde } \\ \text { M-LT: } & \text { Medium-dose L-theanine group } \\ \text { MOD: } & \text { Model group } \\ \text { NF- } \kappa \text { B (p65), nNOS: } & \text { Neuronal nitric oxide synthase } \\ \text { NOS: } & \text { Nitric oxide synthase } \\ \text { PGC- } 1 \alpha: & \text { Peroxisome proliferator-activated } \\ & \text { receptor- } \gamma \text { coactivator- } 1 \alpha \\ \text { RAGE: } & \text { Receptor for AGEs } \\ \text { ROS: } & \text { Reactive oxygen species } \\ \text { SD: } & \text { Sprague-Dawley } \\ \text { SIRT1: } & \text { Sirtuin } 1 \\ \text { SOD: } & \text { Superoxide dismutase } \\ \text { T-AOC: } & \text { Total antioxidant capacity } \\ \text { TNF- } \alpha: & \text { Tumor necrosis factor- } \alpha .\end{array}$

\section{Data Availability}

The data used to support the findings of this study are included within the article.

\section{Conflicts of Interest}

The authors declare no competing financial interest.

\section{Acknowledgments}

This work was financially supported by the National Natural Science Foundation of China (No. 31871804), the Natural Science Foundation of Hunan Province, China (No. 2019JJ40272 and 2020JJ4036), and the Scientific Research Foundation of Shaoyang College, China (No. 2020HX122). We would like to thank Editage (http://online.editage.cn/) for English language editing.

\section{References}

[1] M. Frimat, M. Daroux, R. Litke, R. Nevière, F. J. Tessier, and E. Boulanger, "Kidney, heart and brain: three organs targeted by ageing and glycation," Clinical Science, vol. 131, no. 11, pp. 1069-1092, 2017.

[2] S. A. Palma-Duran, M. D. Kontogianni, A. Vlassopoulos et al., "Serum levels of advanced glycation end-products (AGEs) and the decoy soluble receptor for AGEs (sRAGE) can identify non-alcoholic fatty liver disease in age-, sex- and BMImatched normo-glycemic adults," Metabolism, vol. 83, pp. 120-127, 2018.

[3] J. N. Fawver, H. E. Schall, R. D. Petrofes Chapa, X. Zhu, and I. V. J. Murray, "Amyloid- $\beta$ metabolite sensing: biochemical linking of glycation modification and misfolding," Journal of Alzheimers Disease, vol. 30, no. 1, pp. 63-73, 2012.

[4] B. A. Yankner, T. Lu, and P. Loerch, "The aging brain," Annual Review of Pathology: Mechanisms of Disease, vol. 3, no. 1, pp. 41-66, 2008.

[5] S. Kawanishi, K. Takata, S. Itezono et al., "Bone-marrowderived microglia-like cells ameliorate brain amyloid pathology and cognitive impairment in a mouse model of Alzheimer's disease," Journal of Alzheimer's Disease, vol. 64, no. 2, pp. 563-585, 2018.

[6] S. W. Pimplikar, R. A. Nixon, N. K. Robakis, J. Shen, and L. H. Tsai, "Amyloid-independent mechanisms in Alzheimer's dis- ease pathogenesis," The Journal of Neuroscience, vol. 30, no. 45, pp. 14946-14954, 2010.

[7] V. Srikanth, A. Maczurek, T. Phan et al., "Advanced glycation endproducts and their receptor RAGE in Alzheimer's disease," Neurobiology of Aging, vol. 32, no. 5, pp. 763-777, 2011.

[8] K. Byun, Y. Yoo, M. Son et al., "Advanced glycation endproducts produced systemically and by macrophages: a common contributor to inflammation and degenerative diseases," Pharmacology \& therapeutics, vol. 177, pp. 44-55, 2017.

[9] C. Ott, K. Jacobs, E. Haucke, A. Navarrete Santos, T. Grune, and A. Simm, "Role of advanced glycation end products in cellular signaling," Redox Biology, vol. 2, pp. 411-429, 2014.

[10] R. D. Semba, E. J. Nicklett, and L. Ferrucci, "Does accumulation of advanced glycation end products contribute to the aging phenotype?," The Journals of Gerontology. Series A, Biological Sciences and Medical Sciences, vol. 65, no. 9, pp. 963975,2010

[11] F. Ledl and E. Schleicher, "New aspects of the Maillard reaction in foods and in the human body," Angewandte Chemie International Edition, vol. 29, no. 6, pp. 565-594, 1990.

[12] X. Song, M. Bao, D. Li, and Y. M. Li, "Advanced glycation in dgalactose induced mouse aging model," Mechanisms of Ageing and Development, vol. 108, no. 3, pp. 239-251, 1999.

[13] T. Shwe, W. Pratchayasakul, N. Chattipakorn, and S. C. Chattipakorn, "Role of D-galactose-induced brain aging and its potential used for therapeutic interventions," Experimental gerontology, vol. 101, pp. 13-36, 2018.

[14] A. Z. Herskovits and L. Guarente, "SIRT1 in neurodevelopment and brain senescence," Neuron, vol. 3, no. 81, pp. 471483, 2014.

[15] J. Gao, R. Zhou, X. You et al., "Salidroside suppresses inflammation in a D-galactose-induced rat model of Alzheimer's disease via SIRT1/NF- $\kappa$ B pathway," Metabolic Brain Disease, vol. 31, no. 4, pp. 771-778, 2016.

[16] Q. Li, J. Zeng, M. Su, Y. He, and B. Zhu, “Acetylshikonin from Zicao attenuates cognitive impairment and hippocampus senescence in D-galactose-induced aging mouse model via upregulating the expression of SIRT1," Brain Research Bulletin, vol. 137, pp. 311-318, 2018.

[17] L. Tapia-Arancibia, E. Aliaga, M. Silhol, and S. Arancibia, "New insights into brain BDNF function in normal aging and Alzheimer disease," Brain Research Reviews, vol. 59, no. 1, pp. 201-220, 2008.

[18] C. Molinari, V. Morsanuto, S. Ruga et al., "The Role of BDNF on Aging-Modulation Markers," Brain Sci, vol. 10, no. 5, p. $285,2020$.

[19] H. Jeong, D. E. Cohen, L. Cui et al., "Sirt1 mediates neuroprotection from mutant huntingtin by activation of the TORC1 and CREB transcriptional pathway," Nature Medicine, vol. 18, no. 1, pp. 159-165, 2011.

[20] C. Harrison, "A neuroprotective role for sirtuin 1," Nature Reviews Drug Discovery, vol. 11, no. 2, p. 108, 2012.

[21] X. Peng, J. Ma, F. Chen, and M. Wang, "Naturally occurring inhibitors against the formation of advanced glycation end-products," Food \& Function, vol. 2, no. 6, pp. 289301, 2011.

[22] M. I. Prasanth, B. S. Sivamaruthi, C. Chaiyasut, and T. Tencomnao, "A review of the role of green tea (Camellia sinensis) in antiphotoaging, stress resistance, neuroprotection, and autophagy," Nutrients, vol. 11, no. 2, p. 474, 2019. 
[23] S.-Q. Chen, Z.-S. Wang, Y.-X. Ma et al., "Neuroprotective effects and mechanisms of tea bioactive components in neurodegenerative diseases," Molecules, vol. 23, no. 3, 2018.

[24] E. Sharma, R. Joshi, and A. Gulati, "L-Theanine: an astounding sui generis integrant in tea," Food Chemistry, vol. 242, pp. 601610, 2018.

[25] A. Culetu, B. Fernandez-Gomez, M. Ullate, M. D. del Castillo, and W. Andlauer, "Effect of theanine and polyphenols enriched fractions from decaffeinated tea dust on the formation of Maillard reaction products and sensory attributes of breads," Food Chemistry, vol. 197, no. 197, pp. 14-23, 2016.

[26] L. Zeng, L. Lin, Y. Peng et al., "l-Theanine attenuates liver aging by inhibiting advanced glycation end products in $\mathrm{d}$ galactose-induced rats and reversing an imbalance of oxidative stress and inflammation," Experimental Gerontology, vol. 131, article 110823, 2020.

[27] L. Lin, L. Zeng, A. Liu et al., "L-Theanine regulates glucose, lipid, and protein metabolism via insulin and AMP-activated protein kinase signaling pathways," Food \& Function, vol. 11, no. 2, pp. 1798-1809, 2020.

[28] C. López-Otín, M. A. Blasco, L. Partridge, M. Serrano, and G. Kroemer, "The hallmarks of aging," Cell, vol. 153, no. 6, pp. 1194-1217, 2013.

[29] L. Pastorino and K. P. Lu, "Pathogenic mechanisms in Alzheimer's disease," European Journal of Pharmacology, vol. 545, no. 1, pp. 29-38, 2006.

[30] V. Srikanth, B. Westcott, J. Forbes et al., "Methylglyoxal, cognitive function and cerebral atrophy in older people," The Journals of Gerontology Series A: Biological Sciences and Medical Sciences, vol. 68, no. 1, pp. 68-73, 2013.

[31] H. Zhao, N. Li, Q. Wang, X. J. Cheng, X. M. Li, and T. T. Liu, "Resveratrol decreases the insoluble $A \beta 1-42$ level in hippocampus and protects the integrity of the blood-brain barrier in AD rats," Neuroscience, vol. 310, pp. 641-649, 2015.

[32] S. U. Rehman, S. A. Shah, T. Ali, J. I. Chung, and M. O. Kim, "Anthocyanins reversed D-Galactose-induced oxidative stress and neuroinflammation mediated cognitive impairment in adult rats," Molecular Neurobiology, vol. 54, no. 1, pp. 255271, 2017.

[33] T. I. Kim, Y. K. Lee, S. G. Park et al., "l-Theanine, an amino acid in green tea, attenuates $\beta$-amyloid-induced cognitive dysfunction and neurotoxicity: reduction in oxidative damage and inactivation of ERK/p38 kinase and NF- $\kappa \mathrm{B}$ pathways," Free Radical Biology \& Medicine, vol. 47, no. 11, pp. 1601-1610, 2009.

[34] X. di, J. Yan, Y. Zhao et al., "L-Theanine protects the APP (Swedish mutation) transgenic SH-SY5Y cell against glutamate-induced excitotoxicity via inhibition of the NMDA receptor pathway," Neuroscience, vol. 168, no. 3, pp. 778786, 2010.

[35] F. Ahmed, S. Manjunath, and J. N. Narendra Sharath Chandra, "Acetylcholine and memory-enhancing activity of Ficus racemosa bark," Pharmacognosy Research, vol. 3, no. 4, pp. 246249, 2011.

[36] T. I. Kim, D. Y. Yuk, S. G. Park et al., "Improvement of memory impairment by the combination of green tea extract and L-theanine through inhibition of acetylcholinesterase activity in mice," Laboratory Animal Research, vol. 24, pp. 87-92, 2008.
[37] T. Kimura, J. Takamatsu, N. Araki et al., "Are advanced glycation end-products associated with amyloidosis in Alzheimer's disease?," Neuroreport, vol. 6, no. 6, pp. 866-868, 1995.

[38] T. Finkel and N. J. Holbrook, "Oxidants, oxidative stress and the biology of ageing," Nature, vol. 408, no. 6809, pp. 239247, 2000.

[39] J. Budni, M. L. Garcez, F. Mina et al., "The oral administration of D-galactose induces abnormalities within the mitochondrial respiratory chain in the brain of rats," Metabolic Brain Disease, vol. 32, no. 3, pp. 811-817, 2017.

[40] J. W. Pak, A. Herbst, E. Bua, N. Gokey, D. McKenzie, and J. M. Aiken, "Mitochondrial DNA mutations as a fundamental mechanism in physiological declines associated with aging," Aging Cell, vol. 2, no. 1, pp. 1-7, 2003.

[41] R. X. Santos, S. C. Correia, X. Zhu et al., "Mitochondrial DNA oxidative damage and repair in aging and Alzheimer's disease," Antioxidants \& Redox Signaling, vol. 18, no. 18, pp. 2444-2457, 2013.

[42] T. Wenz, "Mitochondria and PGC-1 $\alpha$ in aging and ageassociated diseases," Journal of Aging Research, vol. 2011, no. 4, Article ID 810619, 12 pages, 2011.

[43] K. Anil, P. Atish, and D. Samrita, "Naringin alleviates cognitive impairment, mitochondrial dysfunction and oxidative stress induced by D-galactose in mice," Food and Chemical Toxicology, vol. 48, no. 2, pp. 626-632, 2010.

[44] I. Casetta, V. Govoni, and E. Granieri, "Oxidative stress, antioxidants and neurodegenerative diseases," Current Pharmaceutical Design, vol. 11, no. 16, pp. 2033-2052, 2005.

[45] P. Ben, Z. Zhang, Y. Zhu et al., "L-Theanine attenuates cadmium-induced neurotoxicity through the inhibition of oxidative damage and tau hyperphosphorylation," Neurotoxicology, vol. 57, pp. 95-103, 2016.

[46] M.-R. Jo, M.-H. Park, D.-Y. Choi et al., "Neuroprotective effect of L-theanine on $\mathrm{A} \beta$-induced neurotoxicity through antioxidative mechanisms in SK-N-SH and SK-N-MC cells," Biomolecules \& Therapeutics, vol. 19, no. 3, pp. 288-295, 2011.

[47] P. L. McGEER and M. Eg, "Inflammation and the degenerative diseases of aging," Annals of the New York Academy of Sciences, vol. 1035, no. 1, pp. 104-116, 2004.

[48] E. S. Cannizzo, C. C. Clement, R. Sahu, C. Follo, and L. Santambrogio, "Oxidative stress, inflamm-aging and immunosenescence," Journal of Proteomics, vol. 74, no. 11, pp. 23132323, 2011.

[49] S. Vasto, G. Candore, C. R. Balistreri et al., "Inflammatory networks in ageing, age-related diseases and longevity," Mechanisms of Ageing and Development, vol. 128, no. 1, pp. 83-91, 2007.

[50] M. S. Hayden and S. Ghosh, "Shared principles in NF- $\kappa$ B signaling," Cell, vol. 132, no. 3, pp. 344-362, 2008.

[51] V. Bortolotto and M. Grilli, "Every cloud has a silver lining: proneurogenic effects of $\mathrm{A} \beta$ oligomers and HMGB-1 via activation of the RAGE-NF- $\kappa \mathrm{B}$ axis," CNS \& Neurological Disorders Drug Targets, vol. 16, no. 10, pp. 1066-1079, 2017.

[52] S. Jamwal and P. Kumar, "L-theanine, a component of green tea prevents 3-nitropropionic acid (3-NP)-induced striatal toxicity by modulating nitric oxide pathway," Molecular Neurobiology, vol. 54, no. 3, pp. 2327-2337, 2017.

[53] T. Sumathi, D. Asha, G. Nagarajan, A. Sreenivas, and R. Nivedha, "L-Theanine alleviates the neuropathological changes induced by PCB (Aroclor 1254) via inhibiting 
upregulation of inflammatory cytokines and oxidative stress in rat brain," Environmental Toxicology and Pharmacology, vol. 42, pp. 99-117, 2016.

[54] S. M. Mooney and M. W. Miller, "Expression of bcl-2, bax, and caspase- 3 in the brain of the developing rat," Developmental Brain Research, vol. 123, no. 2, pp. 103-117, 2000.

[55] H. S. Cho, S. Kim, S. Y. Lee, J. A. Park, S. J. Kim, and H. S. Chun, "Protective effect of the green tea component, L-theanine on environmental toxins-induced neuronal cell death," Neurotoxicology, vol. 29, no. 4, pp. 656-662, 2008.

[56] M. J. Webster, C. S. Weickert, M. M. Herman, and J. E. Kleinman, "BDNF mRNA expression during postnatal development, maturation and aging of the human prefrontal cortex," Developmental Brain Research, vol. 139, no. 2, pp. 139-150, 2002.

[57] M. Stepanichev, M. Onufriev, V. Aniol et al., "Effects of cerebrolysin on nerve growth factor system in the aging rat brain," Restorative Neurology and Neuroscience, vol. 35, no. 6, pp. 571-581, 2017.

[58] D. Silakarma and A. A. R. Sudewi, "The role of brain-derived neurotrophic factor (BDNF) in cognitive functions," Bali Medical Journal, vol. 8, no. 2, pp. 427-434, 2019.

[59] E. J. Koh, K. J. Kim, J. Choi, D. H. Kang, and B. Y. Lee, “_Spirulina maxima_ extract prevents cell death through BDNF activation against amyloid beta 1-42 (A $\left.\beta_{1-42}\right)$ induced neurotoxicity in PC12 cells," Neuroscience letters, vol. 673, pp. 33-38, 2018.

[60] M. Bomba, A. Granzotto, V. Castelli et al., "Exenatide reverts the high-fat-diet-induced impairment of BDNF signaling and inflammatory response in an animal model of Alzheimer's disease," Journal of Alzheimer's Disease, vol. 70, no. 3, pp. 793-810, 2019.

[61] D. Y. Xia, X. Huang, C. F. Bi, L. L. Mao, L. J. Peng, and H. R. Qian, "PGC- $1 \alpha$ or FNDC5 is involved in modulating the effects of $A \beta 1-42$ oligomers on suppressing the expression of BDNF, a beneficial factor for inhibiting neuronal apoptosis, $\mathrm{A} \beta$ deposition and cognitive decline of APP/PS1 Tg Mice," Frontiers in Aging Neuroscience, vol. 9, 2017.

[62] M. Azimi, R. Gharakhanlou, N. Naghdi, D. Khodadadi, and S. Heysieattalab, "Moderate treadmill exercise ameliorates amyloid- $\beta$-induced learning and memory impairment, possibly via increasing AMPK activity and up-regulation of the PGC-1 $\alpha /$ FNDC5/BDNF pathway," Peptides, vol. 102, pp. 7888, 2018.

[63] X. X. Kong, R. Wang, X. J. Liu et al., "Function of SIRT1 in physiology," Biochemistry, vol. 74, no. 7, pp. 703-708, 2009.

[64] D. H. Lee, "Sirt1 as a new therapeutic target in metabolic and age-related diseases," Chonnam Medical Journal, vol. 46, no. 2, pp. 67-73, 2010.

[65] K. Yaffe, K. Lindquist, A. V. Schwartz et al., "Advanced glycation end product level, diabetes, and accelerated cognitive aging," Neurology, vol. 77, no. 14, pp. 1351-1356, 2011.

[66] M. W. Poulsen, R. V. Hedegaard, J. M. Andersen et al., "Advanced glycation endproducts in food and their effects on health," Food and Chemical Toxicology, vol. 60, pp. 10-37, 2013.

[67] F. Yeung, J. E. Hoberg, C. S. Ramsey et al., "Modulation of NF$\kappa \mathrm{B}$-dependent transcription and cell survival by the SIRT1 deacetylase," The EMBO journal, vol. 23, no. 12, pp. 23692380, 2004.
[68] A. Salminen and K. Kaarniranta, "AMP-activated protein kinase (AMPK) controls the aging process via an integrated signaling network," Ageing Research Reviews, vol. 11, no. 2, pp. 230-241, 2012.

[69] C. Cantó, Gerhart-Hines, J. N. Feige et al., “AMPK regulates energy expenditure by modulating $\mathrm{NAD}^{+}$metabolism and SIRT1 activity," Nature, vol. 458, no. 7241, pp. 1056-1060, 2009. 